\title{
Identification of storm surge events over the German Bight from atmospheric reanalysis and climate model data
}

\author{
D. J. Befort ${ }^{1,2}$, M. Fischer ${ }^{1}$, G. C. Leckebusch ${ }^{2,1}$, U. Ulbrich ${ }^{1}$, A. Ganske ${ }^{4}$, G. Rosenhagen ${ }^{3}$, and H. Heinrich \\ ${ }^{1}$ Institute of Meteorology, Freie Universität Berlin, Berlin, Germany \\ ${ }^{2}$ School of Geography, Earth and Environmental Sciences, University of Birmingham, Birmingham, UK \\ ${ }^{3}$ Deutscher Wetterdienst (DWD), Hamburg, Germany \\ ${ }^{4}$ German Maritime and Hydrographic Agency (BSH), Hamburg, Germany \\ Correspondence to: D. J. Befort (daniel.befort@met.fu-berlin.de)
}

Received: 17 April 2014 - Published in Nat. Hazards Earth Syst. Sci. Discuss.: 04 June 2014

Revised: 17 May 2015 - Accepted: 18 May 2015 - Published: 30 June 2015

\begin{abstract}
A new procedure for the identification of storm surge situations for the German Bight is developed and applied to reanalysis and global climate model data. This method is based on the empirical approach for estimating storm surge heights using information about wind speed and wind direction. Here, we hypothesize that storm surge events are caused by high wind speeds from north-westerly direction in combination with a large-scale wind storm event affecting the North Sea region. The method is calibrated for ERA-40 data, using the data from the storm surge atlas for Cuxhaven. It is shown that using information of both wind speed and direction as well as large-scale wind storm events improves the identification of storm surge events.

To estimate possible future changes of potential storm surge events, we apply the new identification approach to an ensemble of three transient climate change simulations performed with the ECHAM5/MPIOM model under A1B greenhouse gas scenario forcing. We find an increase in the total number of potential storm surge events of about $12 \%$ [(2001-2100)-(1901-2000)], mainly based on changes of moderate events. Yearly numbers of storm surge relevant events show high interannual and decadal variability and only one of three simulations shows a statistical significant increase in the yearly number of potential storm surge events between 1900 and 2100. However, no changes in the maximum intensity and duration of all potential events is determined. Extreme value statistic analysis confirms no frequency change of the most severe events.
\end{abstract}

\section{Introduction}

Storm surges at the German coast have a high socioeconomic impact, as they are the most dangerous hazard for the coastal areas, even affecting the densely populated urban region of Hamburg.

The factors influencing storm surges are summarized in Weisse et al. (2012) and the knowledge about past and possible future changing storm-surge statistics is reviewed in von Storch and Woth (2008). Winds blowing from offshore directions cause a rise in water levels at the coast, which is particularly relevant during high tides. Other factors influencing the rise of the water level during a storm are local water depth and external surges (Tomczak, 1960; Gönnert and Sossidi, 2011a, b).

The height of a storm surge is defined by the rise of the water level above the mean high water level (MHW). Following the definition used by the German Maritime and Hydrographic Agency (BSH) a storm surge event at the German North Sea coast with water levels exceeding the MHW by 1.5 to $2.5 \mathrm{~m}$ is called a "storm surge", an excess of 2.5 to $3.5 \mathrm{~m}$ is defined as a "heavy storm surge", and an event exceeding $3.5 \mathrm{~m}$ above MHW is called a "very heavy storm surge" (Müller-Navarra et al., 2012). The shape of the German Bight coastline and its estuaries intensifies the water rise as water that is pushed by north-western winds into the southern North Sea is impounded.

The BSH uses dynamical atmospheric and hydrological models to forecast water levels for the German coasts and estuaries. Lately, a dynamical-statistical forecasting system 
was developed (Müller-Navarra et al., 2012). However, until recently, the forecasts were based on an empirical-statistical approach using a multi-linear regression (Müller-Navarra et al., 2003). The formula used in the latter procedure is based on 13 linear equations using wind speed and direction, surface pressure and its change in time, air and/or water temperature, and observed water level in Wick (Scotland) as input data. The factors explaining most of the variability according to these calculations are wind speed and wind direction. The optimal wind direction of $295^{\circ}$, found out for the town of Cuxhaven, in the centre of the German Bight coast, is commonly used as a proxy for the whole region (Jensen et al., 2006). The component of the observed wind projected on this direction is called the "effective wind component" subsequently.

Future changes of extreme water levels during storm surges are both determined by changes of mean sea level and wind storm intensities. Dangendorf et al. (2013) found in an analysis of sea level data from 13 gauges in the German Bight that linear extreme sea level trends exceeded mean sea level trends in the second half of the 20th century, indicating that changes in local extreme winds have played an important role in the recent past. Several recent studies on changes of storm surges under future greenhouse gas (GHG) conditions found only minor or no significant changes for the German and Dutch North Sea coastline (Sterl et al., 2009; Debernard and Roed, 2008; Gaslikova et al., 2013; von Storch and Reichardt, 1997). Other studies found indications of an increase in storm surge extremes at the North Sea coast associated with increased GHG concentrations (Woth et al., 2006; Langenberg et al., 1999). This is in line with Gaslikova et al. (2011), who calculated an increase in insurable losses due to storm surges under future climate scenarios for this region. With respect to wave heights under scenario conditions, Grabemann and Weisse (2008) pointed at increasing extreme wave heights over large parts in the southern and eastern North Sea. This is not a contradiction to findings of de Winter et al. (2012), who found no significant change of projected mean wave heights and periods along the Dutch coasts as there can be different trends in the means and the extremes of an atmospheric phenomenon (see e.g., Ulbrich et al., 2009, 2013; Pinto et al., 2007). Findings from another study focusing on storm surges affecting the English coasts are also inconclusive as trends in surge heights cannot be separated from natural variability (Lowe et al., 2009).

We do not attempt to review the reasons for the different results obtained in detail. Rather, we develop a new methodology for estimating changes in storm surge risks for the German Bight region solely due to changes in frequency and strength of storms under future climate scenario conditions. It is designed to be used with coarse grid data, meeting the current standard of GCM runs in CMIP5 (Taylor et al., 2012). In a first step, the skill of our method is tested by identifying historic storm surge events in reanalysis data. In a second step, we apply the method to the output data of the
CMIP3 ECHAM5/MPIOM simulations under recent and future climate conditions as the requirement of available zonal and meridional wind data at 6 hourly time steps is fulfilled by this model. To estimate the total future storm surge risk in the German Bight, these results can be used to find single events for which corresponding water levels can be calculated and analyzed with regional hydrodynamic models. Thus, we split the future storm surge risk into an atmospheric and an oceanic part and neglect nonlinear interactions of the atmosphere and the ocean.

\section{Data}

For this study we use the storm surge atlas of the station in Cuxhaven (Gönnert and Buß, 2009) covering the period 1901-2008. It comprises a total of 166 storm surges with information about the measured total water level, the calculated astronomical tide and the wind surge. In this study we use the wind surge height, which was computed by subtracting total water height and calculated astronomical tide, thus any other factors like external surges have been neglected. The storm surge atlas only includes those storm surge events for which water levels exceeded the MHW by at least $1.5 \mathrm{~m}$. In context with the tidal amplitude, which is about $2.9 \mathrm{~m}$ for Cuxhaven, this means that even wind surges of the order of a heavy storm surge, following the definition of the BSH, are not fully included in the data, when they occur during low tides. The temporal resolution of time series for total water level, astronomical tide and wind surge is $5 \mathrm{~min}$.

For the calibration of the storm identification method we use the reanalysis data of ERA-40 (Uppala et al., 2005). It covers the period 1957-2002 with a horizontal resolution of $1.125^{\circ}(\approx 125 \mathrm{~km} ; \mathrm{T} 159)$.

In order to estimate changes of storm surge risk, the IPCC-AR4 ensemble simulations of the global coupled atmosphere-ocean model ECHAM5/MPIOM with a horizontal resolution of $1.875^{\circ}(\approx 210 \mathrm{~km}$; T63 $)$ are used. In this study, we investigate the three transient ensemble simulations driven with observed GHG forcing for the period 1900 until 2000 (Röckner et al., 2006d, a; Röckner, 2004b) and A1B scenario forcing for the period 2001 until 2100 (Röckner, 2004a; Röckner et al., 2006b, c). Zonal and meridional surface wind in $10 \mathrm{~m}$ height with a time resolution of $6 \mathrm{~h}$ for ERA-40 reanalysis and ECHAM5 data are analyzed.

\section{Method}

An identification of all wind events potentially leading to extreme storm surges along the German Bight coast is hindered by the coarse resolution of the global climate model simulations in which the German Bight region is represented by about two grid points only. Wind speed data from these grid points may not be representative for a situation with a major 


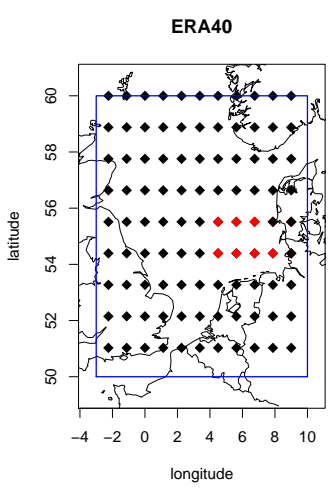

a)

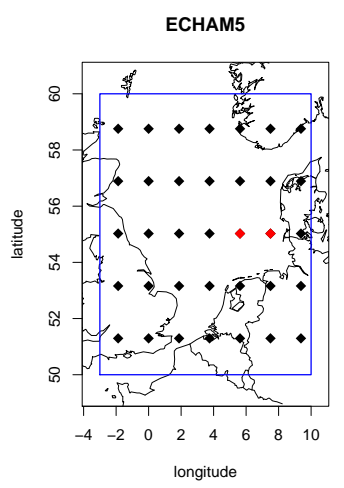

b)

Figure 1. (a) German Bight (red dots) and North Sea region (black dots) for ERA-40 reanalysis. (b) German Bight (red dots) and North Sea region (black dots) for ECHAM5 (T63) data. The blue box defines the boundaries of the North Sea region.

surge-producing storm, potentially including some small and short-lasting events.

In this study, we investigate the improvements of the identification of past storm surge events by additionally taking into account the large-scale wind field over the North Sea region. The advantage of this procedure is investigated in Sect. 4.1.

\subsection{Effective wind component}

As the basis for the identification of storm surge events we apply a method which is based on the statistical approach developed by the German Maritime and Hydrographic Agency (Müller-Navarra et al., 2003). It considers the effective wind component which is the projection of $10 \mathrm{~m}$ winds on the direction of $295^{\circ}$ (WNW direction). In this study, the effective wind component is defined as the mean value calculated using all grid points within the German Bight region, which consists of seven grid points in ERA-40 reanalysis data and two grid points in ECHAM5 model data (Fig. 1a and b). This calculation is done by first calculating the effective wind component at each grid point before averaging over the area.

\subsection{Wind storm identification}

Our identification of large-scale wind storms is based on the methodology described by Leckebusch et al. (2008). This algorithm uses the surface wind speed in a data set, looking for spatially coherent regions with grid points exceeding the local 98th percentile of absolute wind speed for each model time step. Such a storm region is a candidate for a wind storm event if it has a minimum area of about $150000 \mathrm{~km}^{2}(\approx 20$ (7) grid points in ERA-40 (ECHAM5) at $60^{\circ} \mathrm{N}$ ). As it may occur that a wind field cluster with grid boxes exceeding the 98th percentile is decomposed into sub-clusters where none of these fulfill the minimum size required, we use an envelope constructed of the 95th percentile. Thus, even if none of

the individual sub-clusters matches the size criterion solely, it will be counted as a candidate for a wind field track if those sub-clusters are connected through the 95th percentile and the total size of all these sub-clusters exceed the minimum area. These identified clusters are tracked in time using a nearest-neighbour algorithm, obeying a maximum permitted movement of the cluster centre of $600 \mathrm{~km}$ per $6 \mathrm{~h}$ time step, plus an additional allowance for movements of the centre within the cluster (half of the maximum cluster extension). Finally, storm events must have a minimum duration of $18 \mathrm{~h}$.

During the period covered by ERA-40 reanalysis data (1957-2002) 83 storm surges are observed, 82 of which occurred between September and May. Thus, our analysis focuses on the months from September until May as this is the primary season for storm surges in the German Bight area.

Using ERA-40 reanalysis data we calculate the local 98th percentile of $10 \mathrm{~m}$ wind speed over the whole period from 1957 until 2002. To estimate changes in storm surge potential, the 98th percentile for ECHAM5 is calculated using all three ensemble members from the $20 \mathrm{C}$ simulations only. The same percentile value is used to detect storm events during 1900 until 2000 regarding 20C period and 2001 until 2100 for the A1B scenario period, respectively.

\subsection{Method to detect relevant storm surge events}

As no information about the astronomical tide is included in the IPCC-AR4 ECHAM5/MPI-OM simulations, our analysis is based on wind speed and wind direction only. Thus, for observed storm surge events we use the wind surge data from the storm surge catalogue at the station in Cuxhaven only.

In the first step, potential storm surges are identified based on effective wind component values over the German Bight only. In a second step we use additional information about large-scale wind fields. Thus, an event with storm surge potential is characterized by its mean effective wind component over the German Bight region (see Sect. 3.1) and a largescale wind storm event, detected by the algorithm explained (see Sect. 3.2), in the vicinity of the German North Sea coast.

Events are only considered if the large-scale wind storm is located over parts of the North Sea region. This region is illustrated in Fig. 1a and Fig. 1b for ERA-40 reanalysis and ECHAM5 model grids, respectively. In total, the region consists of 99 grid points in ERA-40 and 35 grid points in ECHAM5.

\section{Results}

The analysis is divided into four parts. As a first step, we detect storm surge relevant situations using effective wind components calculated from ERA-40 reanalysis data (Uppala et al., 2005) solely over the German Bight. Using the storm surge catalogue from the station in Cuxhaven (Gönnert 
and Buß, 2009), we assign storm surge events to their effective wind components. Secondly, we use the new method presented in Sect. 3.3, combining effective wind component information and large-scale wind storm events to identify storm surge relevant events. Comparing both methods gives an estimate of the additional value of our proposed methodology. In the third step, this approach is transferred to ECHAM5 model data (Röckner, 2004b, a; Röckner et al., 2006a, b, c, d). Detection of potential storm surge events under recent and future climate conditions gives an estimate of the possible changes in storm surge activity over the German Bight region. In a last step, extreme value statistics are applied to the results of the latter section to calculate return levels for these events, followed by a short conclusion and discussion.

\subsection{Storm surge events in ERA-40 reanalysis data}

Our first attempt in identifying storm surge relevant events in atmospheric model data is based on an empirically derived relationship between observed wind surge and wind speed and direction developed at BSH. First, we calculate effective wind components over the German Bight every $6 \mathrm{~h}$ from ERA-40 reanalysis data. Next, we determine the dates of observed storm surge events from the storm surge atlas of Cuxhaven. As we focus on wind surge, the date assigned to an observed storm surge event is the one at wind surge maximum. In general, no wind data from reanalysis (6 hourly) is available at the exact date of wind surge maximum (every $5 \mathrm{~min}$ ). Thus, we take effective wind component data for the time step before and after wind surge maximum into account. If data with a much higher time resolution were to be used, one would have to think about a $3 \mathrm{~h}$ time lag between wind maximum and surge maximum (Gönnert, 2012). For this study, this will not affect our results. To estimate the usability of this method we count the total number of the 6 hourly time steps in ERA-40 data, for which this threshold of the effective wind component is exceeded. Out of this, we derive the ratio between all observed storm surge events at Cuxhaven and the total number of time steps exceeding this threshold, revealing that only $3.7 \%$ of all time steps in ERA-40 reanalysis data, which exceed the threshold of the effective wind component (observed for the storm surges at Cuxhaven), lead to a storm surge in reality.

As our proposed method is based on the combination of high effective wind components and a large-scale wind storm event, we first identify large-scale storm events with a minimum duration, size and strength in ERA-40 data (see Sect. 3.2). In total, 3541 events are found between September and May for the period 1957 until 2002. This large number is due to the extent of the domain in which wind storm events are identified, covering the region from $35^{\circ} \mathrm{W}$ to $30^{\circ} \mathrm{E}$ and 35 to $75^{\circ} \mathrm{N} .1353$ out of 3541 events have at least one time step with an exceedance of the local 98th percentile over at least one grid point within the North Sea region. As we hypothesize that a large-scale wind storm over the North Sea region is obligatory for the occurrence of a storm surge, only these 1353 events are considered (see Sect. 3.3). Effective wind components over the German Bight for all 1353 largescale wind storm events are derived.

As expected, not all 1353 wind storm events affecting a North Sea grid point led to a high observed wind surge. We identify those events which are associated with a high wind surge at Cuxhaven by looking for a wind field event which is part of an existing wind storm event affecting the North Sea region at the date of the observed wind surge maximum.

There are two possibilities to assign an effective wind component from ERA-40 data to the observed wind surge maxima. The first idea is to take the higher of the two subsequent (6 hourly) values before or after the wind surge maximum. With this approach a frequency distribution of maximum effective wind components for all 1353 large-scale wind storm events affecting the North Sea region and for those which can be assigned to an observed storm surge, can be calculated (Fig. 2a). We find that a large-scale wind storm event can be found for 80 out of 82 storm surge events (red bars in Fig. 2a). This data set suggests that storm surges are characterized by a minimum effective wind component of about $9.45 \mathrm{~m} \mathrm{~s}^{-1}$ in reanalysis data over the German Bight region. Thus, all large-scale wind storm events affecting the North Sea region combined with an effective wind component exceeding $9.45 \mathrm{~m} \mathrm{~s}^{-1}$ are regarded as potential storm surge events (see Sect. 3.3). Note that the maximum effective wind component is not always found at one of the 6 hourly time steps before or after the maximum surge. One of the reasons for this fact could be related to the actual astronomic tide as the effect of high wind speeds is reduced during high tide compared to low tide (Tomczak, 1960). As well, this minimum effective wind component reflects the mean over seven grid points in ERA-40 reanalysis data. Therefore, it is smaller than observed wind speeds at a particular station during storm surges.

In a second approach we assign the highest effective wind component during the whole wind storm event and do not consider only the maximum of the two subsequent values before or after the surge maximum. In this case, the shape of the frequency distribution is slightly changed compared to the first distribution (Fig. 2b).

Similar to the first approach, based on the effective wind component only, we try to assess the usability of the new method. Therefore, we calculate the ratio of all potential storm surge events in ERA-40 reanalysis data and all storm surge events, which could be assigned to a large-scale wind storm. Large-scale wind storm events with effective wind components below about $10 \mathrm{~m} \mathrm{~s}^{-1}$ never lead to an observed storm surge at Cuxhaven (Fig. 2b). This is reasonable as the wind is blowing offshore in case of negative effective wind component values. As illustrated in Fig. 2b, the ratio of those events which are assigned to an observed storm surge and all large-scale wind storm events is increasing with stronger effective wind component values. A large-scale 


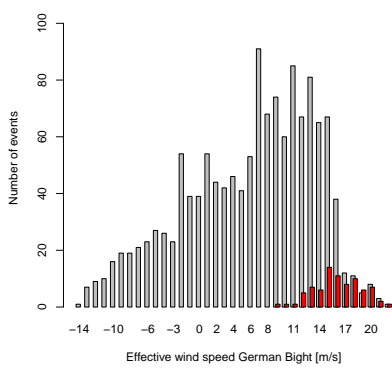

a)

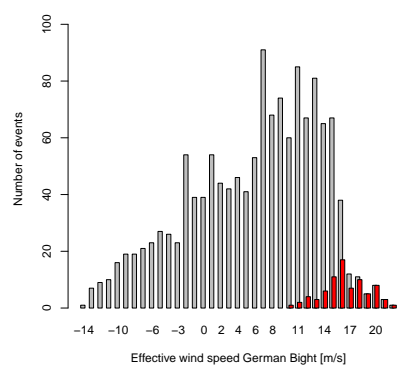

b)
Figure 2. (a) Histogram of effective wind component over the German Bight region for all large-scale wind storm events (grey) and wind storm events which could be assigned to an observed storm surge (red). Effective wind component for assigned events are calculated using the maximum of the ERA-40 time step directly before and after the wind surge maximum. (b) Same as (a) but here effective wind component for assigned events (red) is calculated using the maximum effective wind component during the whole largescale wind storm track.

wind storm event with effective wind components between 10 and $11 \mathrm{~m} \mathrm{~s}^{-1}$ only leads to a storm surge in one percent of all cases. In contrast to this, events with effective wind components between 16.5 and $17.5 \mathrm{~m} \mathrm{~s}^{-1}$ lead in about $50 \%$, and events with effective wind components exceeding about $19 \mathrm{~m} \mathrm{~s}^{-1}$ always lead to an observed storm surge at Cuxhaven. Thus, wind surge tends to exceed tidal amplitudes with increasing effective wind components.

The large number of storms with comparably low effective wind components, which could not be assigned to an observed storm surge, could be caused by the effect that we neglected the interaction between the tide and the winds. Furthermore, the storm surge catalogue from the Cuxhaven station only lists events which led to a minimum total water height of $1.5 \mathrm{~m}$ above MHW. Thus, even if a high wind surge is present but it does not occur during a favourable tide phase, this threshold for total water height is not reached and the event is not included in the storm surge catalogue. Events with effective wind components (larger than $19 \mathrm{~m} \mathrm{~s}^{-1}$ ) cause a very high wind surge, thus leading to a storm surge (exceeding the criterion of $1.5 \mathrm{~m}$ above MHW) independent of the tidal phase.

Two observed storm surge events could not be assigned to a large-scale wind storm event over the North Sea. One of these events is characterized by a large-scale wind storm event which is too short, lasting only two time steps. In the second case, two separated wind fields exist whereof one is located over the North Sea and the other one is located over Scandinavia. Due to the simple nearest-neighbour algorithm the wind field over Scandinavia is connected to the existing wind storm event as it is closer to the previous wind field, and the wind field over the North Sea is neglected.

Overall, the approach based on the combination of high effective wind components and large-scale wind storm events over the North Sea region outperforms the approach based on effective wind components solely, which makes this method well suited for coarse resolved GCM data. Thus, the new method based on:

1. a large-scale wind storm event affecting the North Sea region

2. an effective wind component exceeding $9.45 \mathrm{~m} \mathrm{~s}^{-1}$ over the German Bight region

is further used to detect potential storm surge relevant events in ECHAM5 20C and A1B simulations.

\subsection{Potential storm surge events in ECHAM5 20C and A1B}

Due to the coarser spatial resolution of the GCM data with $1.875^{\circ}$ compared to $1.125^{\circ}$ in ERA-40 reanalysis data, we apply some minor changes to the method presented in Sect. 3.3 for the model analysis. Thus, the regions for the German Bight and North Sea used for the identification in ECHAM5 are not the same regions used in ERA-40. Section 4.1 shows that storm surge events do occur when the spatial mean of the ERA-40 effective wind component over the German Bight exceeds $9.45 \mathrm{~m} \mathrm{~s}^{-1}$ in combination with a large-scale storm field over the North Sea region. As absolute wind speeds can essentially differ between spatially lower resolved model and reanalysis data, we use percentile values rather than absolute wind speed values. An effective wind component of $9.45 \mathrm{~m} \mathrm{~s}^{-1}$ in ERA-40 reanalysis data corresponds to a percentile value of $91.97 \%$. The 91.97 th percentile of effective wind component over the German Bight in ECHAM5 data corresponds to an absolute wind speed of $9.84 \mathrm{~m} \mathrm{~s}^{-1}$. To calculate this value we use the $20 \mathrm{C}$ realizations solely.

\subsubsection{Number of potential storm surge events}

The number of events within the whole identification area covering parts of the North Atlantic is statistically significantly lower during the A1B period with respect to the 20C period (see Table 1). However, the increased number of events with at least one time step within the North Sea region during the A1B period, found for two out of three ensemble members, could indicate a shift in the cyclone tracks. Considering the sum of all three ensemble members of the 20C and A1B period, we find an increase in potential storm surge events affecting the North Sea region (with effective wind component above $9.84 \mathrm{~m} \mathrm{~s}^{-1}$ ) by $12.4 \%$ in A1B compared to $20 \mathrm{C}$.

We calculate the number of all potential storm surge events (effective wind component above $9.84 \mathrm{~m} \mathrm{~s}^{-1}$ ) in ECHAM5 $20 \mathrm{C}$ and A1B data for all ensemble members depending on their effective wind components (Fig. 3). For the majority of classes the number of storm events in A1B has increased with respect to those of the 20C simulations (Fig. 3). 
Table 1. Mean number of events per year within the whole identification area (top line), events with at least one time step within the North Sea (NS) region (middle line) and the amount of potential storm surge events (large-scale wind storm affecting North Sea region + effective wind component above $9.45 \mathrm{~m} \mathrm{~s}^{-1}$ (ERA-40), $9.84 \mathrm{~m} \mathrm{~s}^{-1}$ (ECHAM5) respectively, bottom line) for ERA40 (1957-2002) and for each scenario run of ECHAM5 20C (1900-2000) and ECHAM5 A1B (2001-2100).

\begin{tabular}{lccccccc}
\hline Data & ERA40 & 20C 1 & 20C 2 & 20C 3 & A1B 1 & A1B 2 & A1B 3 \\
\hline Total storm events & 77.0 & 88.2 & 88.1 & 88.2 & 83.1 & 83.3 & 83.5 \\
Events with wind storm over NS & 29.4 & 29.0 & 28.7 & 29.8 & 29.8 & 30.1 & 28.9 \\
Potential storm surge events & 11.0 & 9.6 & 10.1 & 10.7 & 11.4 & 12.0 & 10.8 \\
with wind storm over NS and & & & & & & & \\
$v_{\text {eff }}>9.45 \mathrm{~m} \mathrm{~s}^{-1}$ (ERA-40) or, & & & & & & & \\
$v_{\text {eff }}>9.84 \mathrm{~m} \mathrm{~s}^{-1}$ (ECHAM5) & & & & & & & \\
\hline
\end{tabular}

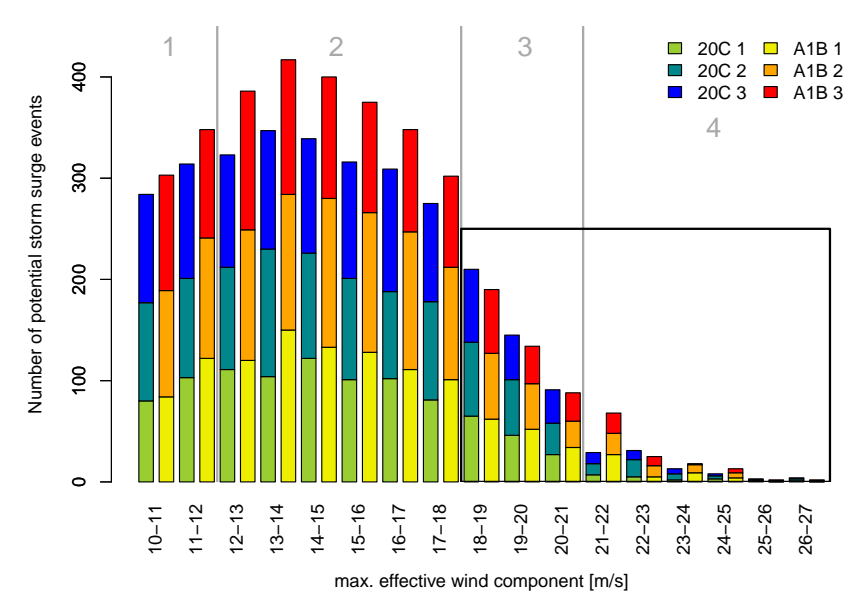

Figure 3. Number of potential storm surge events with respect to their maximum effective wind component over the German Bight region for the three ensemble members of the 20C (19012000, green to blue) and A1B (2001-2100, yellow to red) period. Grey bars denote the boundaries of the four categories used in Sect. 4.2. The black rectangle indicates those potential storm surge classes, which are used for the extreme value statistic described in Sect. 4.2.3.

A high increase of at least $10 \%$ is found for events with effective wind components of $11.8-16.8 \mathrm{~m} \mathrm{~s}^{-1}$. Extreme events in particular, with effective wind components of $20.8-$ $21.8 \mathrm{~m} \mathrm{~s}^{-1}$ become more frequent. However, the storms with effective wind components of 17.8-20.8 and 21.8-22.8 $\mathrm{m} \mathrm{s}^{-1}$ become infrequent for the A1B runs (see Fig. 3). For storms with an effective wind component above $23.84 \mathrm{~ms}^{-1}$, the percentage changes are insignificant due to the low numbers of events. A Kolmogorow-Smirnow test with an error probability of $\alpha=0.05$ reveals that the distributions (for 20C and A1B) cannot be distinguished.

The annual numbers of all potential storm surge events for all three ensemble members for the period 1900 until 2100 are shown in Fig. 4a. The ensemble mean of the ensemble members (black lines) of the 20C scenario (green to blue) and the A1B scenario (yellow to red) reveals a statistically significant linear trend with an error probability of $\alpha=0.01$ and an increase in relevant storm surge events of almost 1.5 events per 200 years within the period 1900-2100. By considering the three runs separately, the relevance of the simulated decadal climate fluctuations is shown: run 1 offers a significant increase of almost three events in 200 years with an error probability of $\alpha=0.001$. In run 2 a rise is seen as well which, however, is not statistically significant. Run 3 shows a slight decrease which is also not statistically significant. However, taken into account the large interannual fluctuations in the range between two and 28 events per year, the increase of even three events in 200 years is very moderate.

As discussed in Sect. 4.1, the probability of a potential wind storm event leading to a storm surge increases for stronger effective wind components. Thus, we divide all potential storm surge events into four categories dependent on the effective wind component value: (1) weak $\left(<12 \mathrm{~ms}^{-1}\right)$, (2) moderate (between $12 \mathrm{~m} \mathrm{~s}^{-1}$ and $18 \mathrm{~ms}^{-1}$ ), (3) strong (between $18 \mathrm{~m} \mathrm{~s}^{-1}$ and $21 \mathrm{~m} \mathrm{~s}^{-1}$ ), and (4) very strong (above $\left.22 \mathrm{~m} \mathrm{~s}^{-1}\right)$. We find an increase for three categories $(1,2,4)$ as well as for the total number of potential storm surge events under future climate conditions (Table 2). However, only the total number as well as the number of moderate events (category 2) differ significantly under the assumption of a Poisson distributed variable. Using results shown in Sect. 4.1, weak potential storm surge events only lead to a storm surge in Cuxhaven in $2 \%$ of the cases, and moderate events in $13.7 \%$ of the cases. In contrast, it is found that strong events are in $87.5 \%$ and very strong events in $100 \%$ of all cases related to a storm surge.

We find no significant trend of the annual number of weak (category 1) potential storm surge events as well as for strong (category 3) potential storm surge events (Fig. 4b and d). For these two categories none of the three ensemble members shows a significant increase or decrease. We find for the ensemble mean a statistically significant increase for moderate events (category 2) of about 1.17 events (with an error probability of $\alpha=0.05$ ) and an increase for very strong events (category 4 ) of about 0.29 with an error probability of $\alpha=0.01$ (Fig. 4c and e). For these two categories two out 


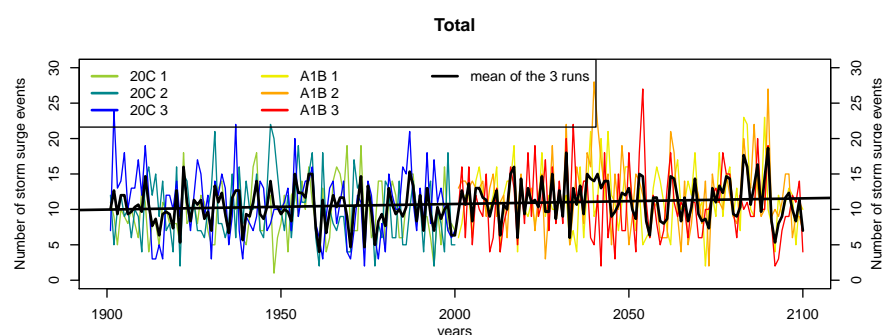

a)

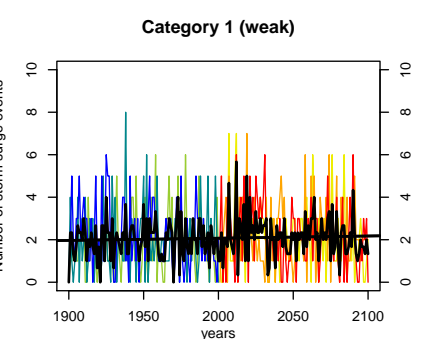

b)

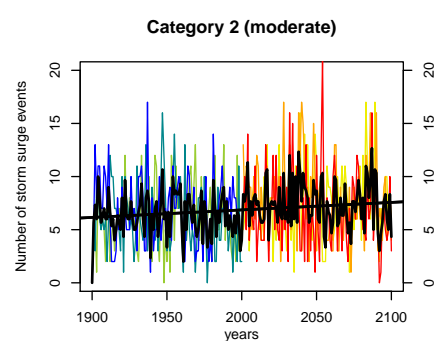

c)

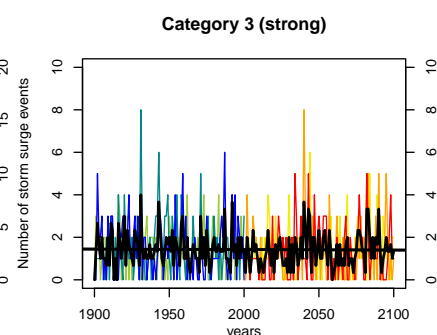

d)

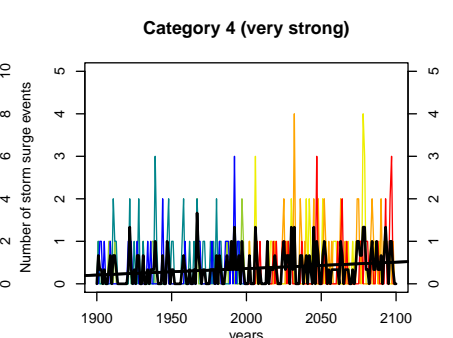

e)

Figure 4. Annual number of potential storm surge events from 1900 to 2100 for the scenario runs of 20C (green to blue) and A1B (yellow to red). The black lines denote the ensemble mean for (a) all potential storm surge events, (b) weak potential storm surge events (category 1), (c) moderate potential storm surge events (category 2), (d) strong potential storm surge events (category 3) and (e) very strong potential storm surge events (category 4).

Table 2. Percental changes in the number of potential storm surge events of all three ensemble members during 2001-2100 (A1B) compared to the 1901-2000 (20C) for the four categories and all events. Statistically significant changes are highlighted.

\begin{tabular}{lrr}
\hline Category & Effective Wind Component & Increase [\%] \\
\hline Category 1 (weak) & $9.84-12 \mathrm{~m} \mathrm{~s}^{-1}$ & $+8.86 \%$ \\
Category 2 (moderate) & $12-18 \mathrm{~m} \mathrm{~s}^{-1}$ & $\mathbf{+ 1 6 . 7 1 \%}$ \\
Category 3 (strong) & $18-21 \mathrm{~m} \mathrm{~s}^{-1}$ & $-7.62 \%$ \\
Category 4 (very strong) & $>21 \mathrm{~m} \mathrm{~s}^{-1}$ & $+45.45 \%$ \\
Total & $>9.84 \mathrm{~m} \mathrm{~s}^{-1}$ & $\mathbf{+ 1 2 . 4 3 \%}$ \\
\hline
\end{tabular}

of three ensemble members show a statistically significant increase of the annual number.

It should be noted that changes in very strong potential storm surge events are difficult to assess, as the number of events in this category is very low (20C: 88 ; A1B: 128) and results might depend on the exact classification of potential storm surge events. Overall, the increase in moderate events is more robust due to the higher number of events (20C: 1909 and A1B: 2228). This indicates that the increase of all potential storm surge events (Fig. 4a) is dominated by the changes of moderate events, the latter leading to a storm surge in ERA-40 reanalysis data in about $13.7 \%$ of cases.

In Fig. 5 the 30 year moving mean of the total number of potential storm surge events per year for the considered runs and for the ensemble mean is shown. The large decadal fluctuations can be clearly seen in the time series of the means. Therefore, it has to be noted that the increase in numbers of relevant storms is not monotonic. Furthermore, the 30 year

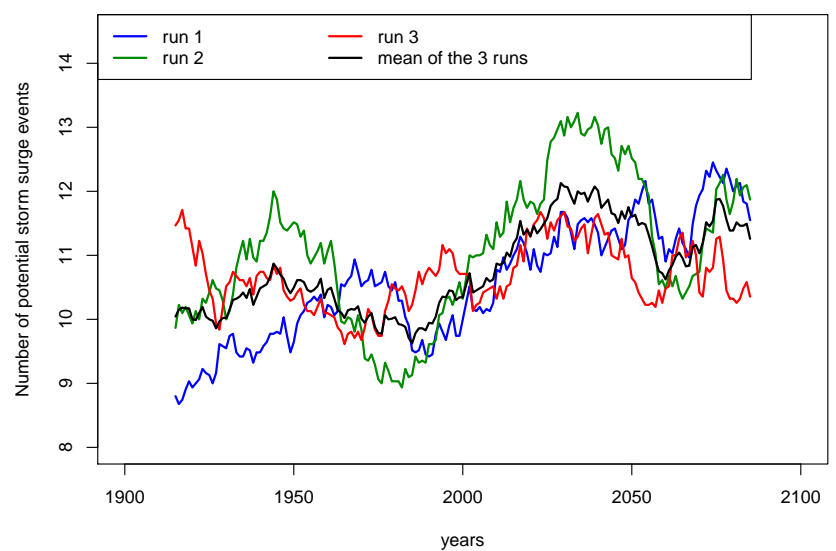

Figure 5. 30 year running mean of the annual number of potential storm surge events from 1915 to 2085 for the three runs (run 1: blue, run 2: green, run 3: red) and for the mean of all ensemble members (black).

periods with the largest numbers of storm surge relevant events are not found at the end of the 21 st century for all three ensemble members.

\subsubsection{Duration of potential storm surge events}

In addition to the number of potential storm surge events, we investigate if the duration of such events changes under future conditions. Therefore, the number of time steps are counted for which the storm is located in the region of the North Sea and the effective wind component of $9.84 \mathrm{~m} \mathrm{~s}^{-1}$ 


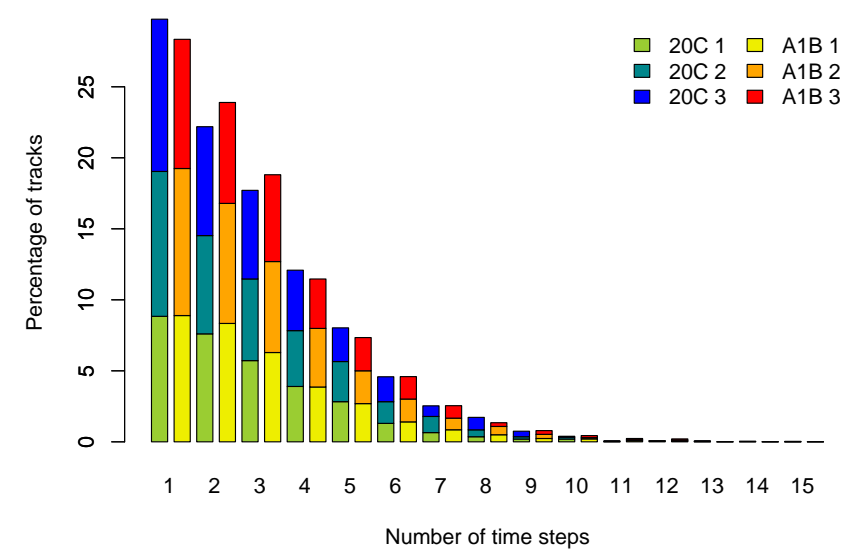

Figure 6. Potential storm surge duration distribution (in \%) with respect to the number of time steps which exceed the critically effective wind component for the three 20C runs (1901-2000, green to blue) and the three A1B runs (2001-2100, yellow to red).

is exceeded. An increased storm surge potential can be assumed due to an increased duration of the events, even if the maximum effective wind component is unchanged. Figure 6 depicts the percentage of exceedings for the runs of $20 \mathrm{C}$ and $\mathrm{A} 1 \mathrm{~B}$ with respect to the total number of tracks in the respective century. However, analysing the uncertainty of the counts (confidence interval of the Poisson distribution) for 20C and A1B shows no evidence for a change of the duration (with an error probability of $\alpha=0.05$ ).

\subsubsection{Return levels of extreme effective wind component}

To investigate the occurrence rate of extreme events, extreme value statistics (EVS) provide a suitable approach. At this point, only the basic idea of the theory is covered and reference is made to more in-depth literature, e.g. Coles (2001). In EVS, extreme values above a certain threshold can be described by using the generalized Pareto distribution (GPD) given by:

$$
\begin{aligned}
& H(y)=1-\left(1+\frac{\xi y}{\widetilde{\sigma}}\right)^{-1 / \xi} \\
& \text { with }\{y: y>0\},(1+\xi y / \widetilde{\sigma})>0,
\end{aligned}
$$

with the form parameter, $\xi$, and the scale parameter, $\widetilde{\sigma}$, which is dependent on the statistical threshold value used for restricting the assessment to extremes. The choice of the threshold is delicate because if the threshold chosen is too high, not enough values for the statistical analysis exist. For a peak-over-threshold approach a selection of an appropriate threshold, $u$, is vital. Guidance for threshold selection is provided by the mean residual life plot (mrlp); if the threshold $u_{0}$ is large enough to ensure the GPD approximation to be valid then, for all thresholds $u>u_{0}$, a linear relationship be- tween the mean of excesses $\mathrm{E}(x-u \mid x>u)$ and the threshold $u$ holds (Coles, 2001).

The mrlp derived by using all three $20 \mathrm{C}$ ensemble members is shown in Fig. 7. In addition to the mean excess (continuous line), their $95 \%$ confidence interval is drawn as well (dotted lines). The red vertical line marks the threshold of $9.84 \mathrm{~m} \mathrm{~s}^{-1}$ derived from historical storm surges (cf. Sect. 4.2) with more than a quarter of the time steps exceeding that threshold. However, based on the mrlp, this threshold is too low to allow for a reliable approximation with the GPD; the plot rather suggests a threshold of $18.0 \mathrm{~m} \mathrm{~s}^{-1}$, because above this threshold the mrlp is approximately linear in $\mathrm{u}$. Thus, the following results solely include strong and very strong storm surge events (category 3 and category 4). It has already been established that a statistically significant and robust change of the total number of events for these two classes does not exist. Furthermore, we cannot identify a trend of the yearly number of strong and very strong potential storm surge events for both categories together. Thus, we use the stationary approach of the GPD. With the threshold of $18.0 \mathrm{~m} \mathrm{~s}^{-1}$ we calculate return levels including all three ensemble members available during A1B and the $20 \mathrm{C}$ period (Fig. 8). In this case the return levels specify the effective wind component in $\mathrm{m} \mathrm{s}^{-1}$ which is expected to be exceeded on average once in a certain return period. As expected, the increased number of potential storm surge events is also reflected in slightly raised return levels on the interannual to interdecadal scale (return levels 0.1-7) for the runs of A1B. The effective wind components, which are expected to be exceeded several times a year are increased by nearly $0.5 \mathrm{~m} \mathrm{~s}^{-1}$ in the $\mathrm{A} 1 \mathrm{~B}$ runs with respect to $20 \mathrm{C}$. On the decadal to multidecadal scale the return levels are higher for $20 \mathrm{C}$ because of a few more events of the strongest intensity classes (Fig. 3). The increased uncertainty of the multi-decadal return levels are expressed by wider confidence intervals. However, the slight differences in the return levels are not significant. Thus, extreme value statistics confirm that strong and very strong storm surge events do not reveal interpretable changes in the future realisation of ECHAM5.

\section{Conclusions}

In this study, changes of the storm surge risk at the German Bight coast caused by possible changes of meteorological parameters under future climate conditions are investigated. In order to detect storm surge events in meteorological reanalysis and climate model data, we use $10 \mathrm{~m}$ wind vectors only. We hypothesize that storm surge events are attributed to strong near surface wind speeds over the German Bight projected on a wind direction of $295^{\circ}$, under the condition of a large-scale wind storm event affecting the North Sea region.

Using ERA-40 reanalysis data and the storm surge atlas for the station Cuxhaven, 80 out of 82 observed storm surge 


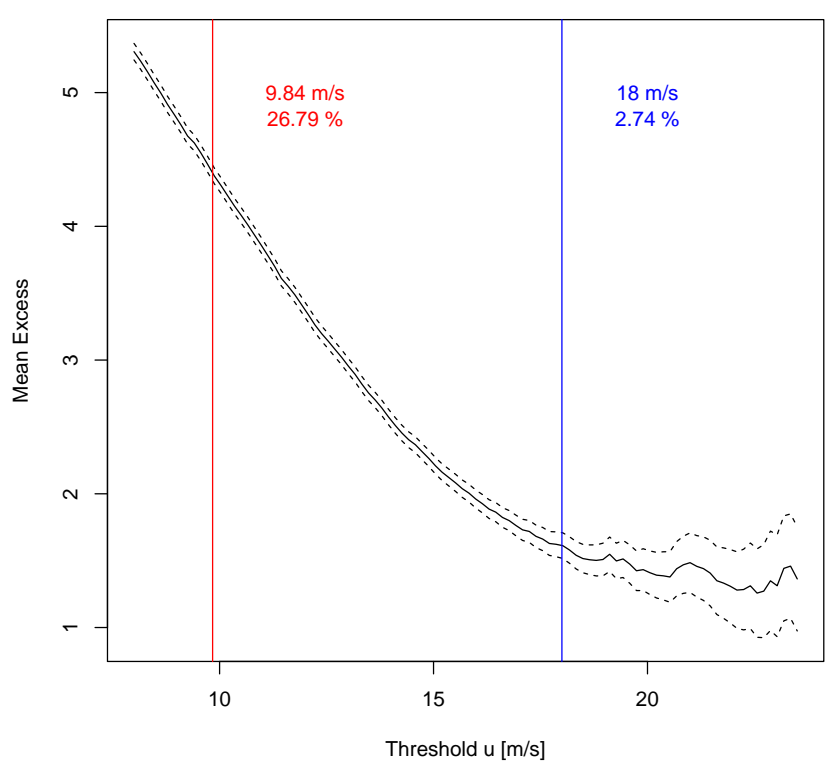

Figure 7. Mean residual life plot for the effective wind component of all three 20C runs. The mean excess (continuous line) and the $95 \%$ confidence intervals (dashed lines) are shown. Thresholds derived from historical storm surge events (red) and derived from the extreme value statistics (blue) are indicated as vertical lines. In addition, the percentage of these exceedings are specified.

events between September and May could be assigned to a large-scale wind storm event. The reason that one event could not be assigned to any storm surge event is due to difficulties arising from the simple nearest-neighbour approach used for the identification of large-scale wind fields. Another event does not fulfill the minimum duration criterion of $18 \mathrm{~h}$.

Our analysis shows that storm surge events are characterized by an effective wind component exceeding $9.45 \mathrm{~m} \mathrm{~s}^{-1}$ in ERA-40, but not every wind event with an effective wind component over $9.45 \mathrm{~m} \mathrm{~s}^{-1}$ leads to an observed storm surge. This is mainly explained by the fact that tides are not taken into account in our approach. As the interaction of tides and high winds are important for the development of a storm surge, it can also be observed that not every storm causes a storm surge. Furthermore, other factors, e.g. external surges are included in the wind surge data as this variable is derived by subtracting the water level and the astronomical tide. Gönnert (2003) showed that in about $20 \%$ of all observed storm surge events the water level is influenced by external surges. However, in most of these cases the wind surge was not in phase with the external surge (Gönnert, 2003).

Nevertheless, if the effective wind component is higher than about $19 \mathrm{~m} \mathrm{~s}^{-1}$, then water levels rise above the criterion height for storm surges, independent of the phase of the tide. In these cases, the respective tidal phase only determines the severeness of the storm surge. For ERA-40 winds, all wind storm events with effective wind components exceeding $19 \mathrm{~m} \mathrm{~s}^{-1}$ can be attributed to an observed storm surge.

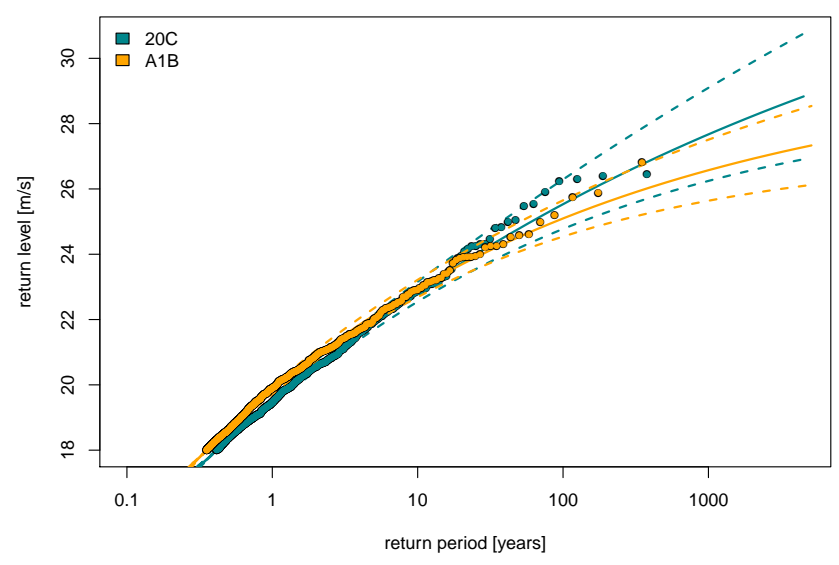

Figure 8. Return levels in $\mathrm{m} \mathrm{s}^{-1}$ ( $y$ axis) for different return periods in years ( $x$ axis) for 20C (1901-2000, turquoise) and A1B (20012100 , orange) + the $95 \%$ confidence intervals (dashed lines). Only effective wind component values exceeding $18 \mathrm{~ms}^{-1}$ are considered.

Thus, higher effective wind components lead to a reduced importance of the tidal phase.

The analysis presented in this paper shows that the proposed method using large-scale wind field information as well as effective wind components over the German Bight enhances the detection of potential storm surge events compared to using effective wind component values solely.

We apply our methodology to three runs of the ECHAM5/MPI-OM simulations forced by observed GHG concentrations for the period 1900 until 2000 and with GHG concentrations following the SRES A1B scenario from 2001 until 2100. As absolute wind speed distributions between model and reanalysis data differ, we do not use the absolute threshold of $9.45 \mathrm{~m} \mathrm{~s}^{-1}$ (derived from ERA-40 data) for the identification of potential storm surge events in ECHAM5 model data. Instead, we use a minimum effective wind component of $9.84 \mathrm{~m} \mathrm{~s}^{-1}$ for ECHAM5 data, corresponding to the same percentile value of $91.97 \%$ as $9.45 \mathrm{~m} \mathrm{~s}^{-1}$ in ERA40.

The total number of potential storm surge events identified in all three simulations under the A1B scenario for the whole period between 2001 and 2100 is increased by $12.4 \%$ with respect to the 20C period (1901-2000). All three time series of yearly numbers of potential storm surge events display a high interannual and decadal variability. Only one simulation shows a significant increase in the number of potential storm surge events per year, while the two others show either an increasing or a decreasing trend, which are both insignificant. We find no increase of the highest effective wind components as well as in the duration of potential storm surge events under future climate conditions.

We divide potential storm surge events identified in ECHAM5 model data into four categories according to their maximum effective wind components. A statistically signif- 
icant increase of the total number of these events is found, which is mainly due to a statistically significant increase of moderate potential storm surge events. According to ERA40 reanalysis data, the probability of these moderate events to cause a storm surge in Cuxhaven is $13.7 \%$.

Extreme value statistics reveal an increase in effective wind components with an interannual to interdecadal scale, whereas events with larger return periods exhibit lower return levels, indicating that the rarest events will potentially show reduced intensity. However, uncertainties are large and do not allow for a meaningful interpretation of the changes in the most severe events.

The increase in the total number of potential storm surge events found in this study cannot directly be compared to other studies including effects of the astronomical tide (e.g., Sterl et al., 2009; de Winter et al., 2012). Nevertheless, Sterl et al. (2009) found no significant increase in storm surge events in Cuxhaven, which is in line with our results showing no changes in the most severe events.

The fact that the proposed method can be easily applied to simulations carried out with different climate models independent of their spatial resolution at low computational costs is the main advantage. Thus, for example, it allows for a preselection of potential storm surge events in coarse resolved data, which can be further dynamically downscaled using regional climate models to investigate local characteristics of these events in more detail.

Acknowledgements. The authors thank the LSBG (Landesbetrieb für Straßen, Brücken und Gewässer) in Hamburg for providing data from the storm surge atlas for the station Cuxhaven as well as ECMWF for providing ERA-40 reanalysis data. This work was funded by the KLIWAS research programme of the Federal Ministry of Transport and Digital Infrastructure (BMVI). The authors thank all three anonymous referees for their constructive comments.

Edited by: I. Didenkulova

Reviewed by: three anonymous referees

\section{References}

Coles, S.: An Introduction to Statistical Modeling of Extreme Values, Springer-Verlag, London, 2001.

Dangendorf, S., Mudersbach, C., Jensen, J., Ganske, A., and Heinrich, H.: Seasonal to decadal forcing of high water level percentiles in the German Bight throughout the last century, Ocean Dynam., 63, 533-548, 2013.

Debernard, J. B. and Roed, L. P.: Future wind, wave and storm surge climate in the Northern Seas: a revisit, Tellus A, 60, 427-438, 2008.

de Winter, R. C., Sterl, A., de Vries, J. W., Weber, S. L., and Ruessink, G.: The effect of climate change on extreme waves in front of the Dutch coast, Ocean Dynam., 62, 1139-1152, 2012.

Gaslikova, L., Schwerzmann, A., Raible, C. C., and Stocker, T. F.: Future storm surge impacts on insurable losses for the North
Sea region, Nat. Hazards Earth Syst. Sci., 11, 1205-1216, doi:10.5194/nhess-11-1205-2011, 2011.

Gaslikova, L., Grabemann, I., and Groll, N.: Changes in North Sea storm surge conditions for four transient future climate realizations, Nat. Hazards, 66, 1501-1518, 2013.

Gönnert, G.: Sturmfluten und Windstau in der Deutschen Bucht Charakter, Veränderungen und Maximalwerte im 20. Jahrhundert, Die Küste - Archiv für Forschung und Technik an der Nordund Ostsee, Heft 67, 185-365, 2003.

Gönnert, G. and Buß, T.: Sturmfluten zur Bemessung von Hochwasserschutzanlagen, Landesbetrieb Straßen, Brücken und Gewässer, Hamburg, 2009.

Gönnert, G. and Sossidi, K.: A new approach to calculate extreme storm surges: analysing the interaction of storm surge components, in: Coastal Processes II, Vol. 149, 139-150, WIT PRESS, Southhampton, 139-150, 2011a.

Gönnert, G. and Sossidi, K.: A new approach to calculate extreme storm surges, Irrig. Drain., 60, 91-98, 2011 b.

Gönnert, G.: Ermittlung des Sturmflutbemessungswasserstandes für den öffentlichen Hochwasserschutz in Hamburg, Landesbetrieb Straßen, Brücken und Gewässer, Hamburg, 2012.

Grabemann, I. and Weisse, R.: Climate change impact on extreme wave conditions in the North Sea: an ensemble study, Ocean Dynam., 58, 199-212, 2008.

Jensen, J., Mudersbach, C., Müller-Navarra, S. H., Bork, I., Koziar, C., and Renner, V.: Modellgestützte Untersuchungen zu Sturmfluten mit sehr geringen Eintrittswahrscheinlichkeiten an der deutschen Nordseeküste, Die Küste, 71, 123-167, 2006.

Langenberg, H., Pfizenmayer, A., von Storch, H., and Sundermann, J.: Storm-related sea level variations along the North Sea coast: natural variability and anthropogenic change, Cont. Shelf Res., 19, 821-842, 1999.

Leckebusch, G. C., Renggli, D., and Ulbrich, U.: Development and application of an objective storm severity measure for the Northeast Atlantic region, Meteorol. Z., 17, 575-587, 2008.

Lowe, J. A., Howard, T., Pardaens, A., Tinker, J., Holt, J., Wakelin, S., Milne, G., Leake, J., Wolf, J., Horsburgh, K., Reeder, T., Jenkins, G.,Ridley, J., Dye, S., and Bradley, S.: UK climate projections science report: Marine and coastal projections, Technical report, Met Office Hadley Centre, Exeter, UK, 2009.

Müller-Navarra, S. H., Lange, W., Dick, S., and Soetje, K. C.: Über die Verfahren der Wasserstands- und Sturmflutvorhersage: hydrodynamisch-numerische Modelle der Nord- und Ostsee und ein empirisch-statistisches Verfahren für die Deutsche Bucht, Promet, 29, 117-124, 2003.

Müller-Navarra, S. H., Seifert, W., Lehmann, H.-A., and Maudrich, S.: Sturmflutvorhersage für Hamburg 1962 und heute, Bundesamt für Seeschifffahrt und Hydrographie, Hamburg und Rostock, 2012.

Pinto, J. G., Ulbrich, U., Leckebusch, G. C., Spangehl, T., Reyers, M., and Zacharias, S.: Changes in storm track and cyclone activity in three SRES ensemble experiments with the ECHAM5/MPI-OM1 GCM, Clim. Dynam., 29, 195-210, 2007.

Röckner, E.: IPCC-AR4 MPI-ECHAM5_T63L31 MPIOM_GR1.5L40 SRESA1B run no.2: atmosphere 6 HOUR values MPImet/MaD Germany, World Data Center for Climate (WDCC), 2004a.

Röckner, E.: IPCC-AR4 MPI-ECHAM5_T63L31 MPIOM_GR1.5L40 20C3M run no.2: atmosphere 6 HOUR 
values MPImet/MaD Germany, World Data Center for Climate (WDCC), 2004b.

Röckner, E., Lautenschlager, M., and Esch, M.: IPCC-AR4 MPIECHAM5_T63L31 MPI-OM_GR1.5L40 20C3M run no.3: atmosphere 6 HOUR values MPImet/MaD Germany, World Data Center for Climate (WDCC), 2006a.

Röckner, E., Lautenschlager, M., and Schneider, H.: IPCC-AR4 MPI-ECHAM5_T63L31 MPI-OM_GR1.5L40 SRESA1B run no.1: atmosphere 6 HOUR values MPImet/MaD Germany, World Data Center for Climate (WDCC), 2006b.

Röckner, E., Lautenschlager, M., and Schneider, H.: IPCC-AR4 MPI-ECHAM5_T63L31 MPI-OM_GR1.5L40 SRESA1B run no.3: atmosphere 6 HOUR values MPImet/MaD Germany, World Data Center for Climate (WDCC), 2006c.

Röckner, E., Lautenschlager, M., and Schneider, H.: IPCC-AR4 MPI-ECHAM5_T63L31 MPI-OM_GR1.5L40 20C3M run no.1: atmosphere 6 HOUR values MPImet/MaD Germany, World Data Center for Climate (WDCC), 2006d.

Sterl, A., van den Brink, H., de Vries, H., Haarsma, R., and van Meijgaard, E.: An ensemble study of extreme storm surge related water levels in the North Sea in a changing climate, Ocean Sci., 5, 369-378, doi:10.5194/os-5-369-2009, 2009.

Taylor, K. E., Stouffer, R. J., and Meehl, G. A.: An Overview of CMIP5 and the Experiment Design, B. Am. Meteorol. Soc., 93, 485-498, doi:10.1175/BAMS-D-11-00094.1, 2012.

Tomczak, G.: Über die Genauigkeit der Sturmflutvorhersage für die deutsche Nordseeküste, Deutsche Hydrografische Z., 13, 1-13, doi:10.1007/BF02224731, 1960.

Ulbrich, U., Leckebusch, G. C., and Pinto, J. G.: Extra-tropical cyclones in the present and future climate: a review, Theor. Appl. Climatol., 96, 117-131, doi:10.1007/s00704-008-0083-8, 2009.
Ulbrich, U., Leckebusch, G. C., Grieger, J., Schuster, M., Akperov, M., Bardin, M. Y., Feng, Y., Gulev, S., Inatsu, M., Keay, K., Kew, S. F., Liberato, M. L. R., Lionello, P., Mokhov, I. I., Neu, U., Pinto, J. G., Raible, C. C., Reale, M., Rudeva, I., Simmonds, I., Tilinina, N. D., Trigo, I. F., Ulbrich, S., Wang, X. L., and Wernli, H.: Are greenhouse gas signals of Northern Hemisphere winter extra-tropical cyclone activity dependent on the identification and tracking algorithm?, Meteorol. Z., 22, 61-68, 2013.

Uppala, S. M., Kållberg, P. W., Simmons, A. J., Andrae, U., Bechtold, V. D. C., Fiorino, M., Gibson, J. K., Haseler, J., Hernandez, A., Kelly, G. A., Li, X., Onogi, K., Saarinen, S., Sokka, N., Allan, R. P., Andersson, E., Arpe, K., Balmaseda, M. A., Beljaars, A. C. M., Berg, L. V. D., Bidlot, J., Bormann, N., Caires, S., Chevallier, F., Dethof, A., Dragosavac, M., Fisher, M., Fuentes, M., Hagemann, S., Hólm, E., Hoskins, B. J., Isaksen, L., Janssen, P. A. E. M., Jenne, R., Mcnally, A. P., Mahfouf, J.F., Morcrette, J.-J., Rayner, N. A., Saunders, R. W., Simon, P., Sterl, A., Trenberth, K. E., Untch, A., Vasiljevic, D., Viterbo, P., and Woollen, J.: The ERA-40 re-analysis, Q. J. Roy. Meteor. Soc., 131, 2961-3012, doi:10.1256/qj.04.176, 2005.

von Storch, H. and Reichardt, H.: A Scenario of Storm Surge Statistics for the German Bight at the Expected Time of Doubled Atmospheric Carbon Dioxide Concentration, J. Climate, 10, 2653 2662, 1997.

von Storch, H. and Woth, K.: Storm surges: perspectives and options, Sustain. Sci., 3, 33-43, doi:10.1007/s11625-008-0044-2, 2008.

Weisse, R., von Storch, H., Niemeyer, H. D., and Knaack, H.: Changing North Sea storm surge climate: an increasing hazard?, Ocean Coast. Manage., 68, 58-68, 2012.

Woth, K., Weisse, R., and von Storch, H.: Climate change and North Sea storm surge extremes: an ensemble study of storm surge extremes expected in a changed climate projected by four different regional climate models, Ocean Dynam., 56, 3-15, 2006. 